\title{
ANALISIS SEGMENTASI PASAR TERHADAP FAKTOR FAKTOR SEGMENTASI PADA TOKO JAJANAN HITS PURWOKERTO
}

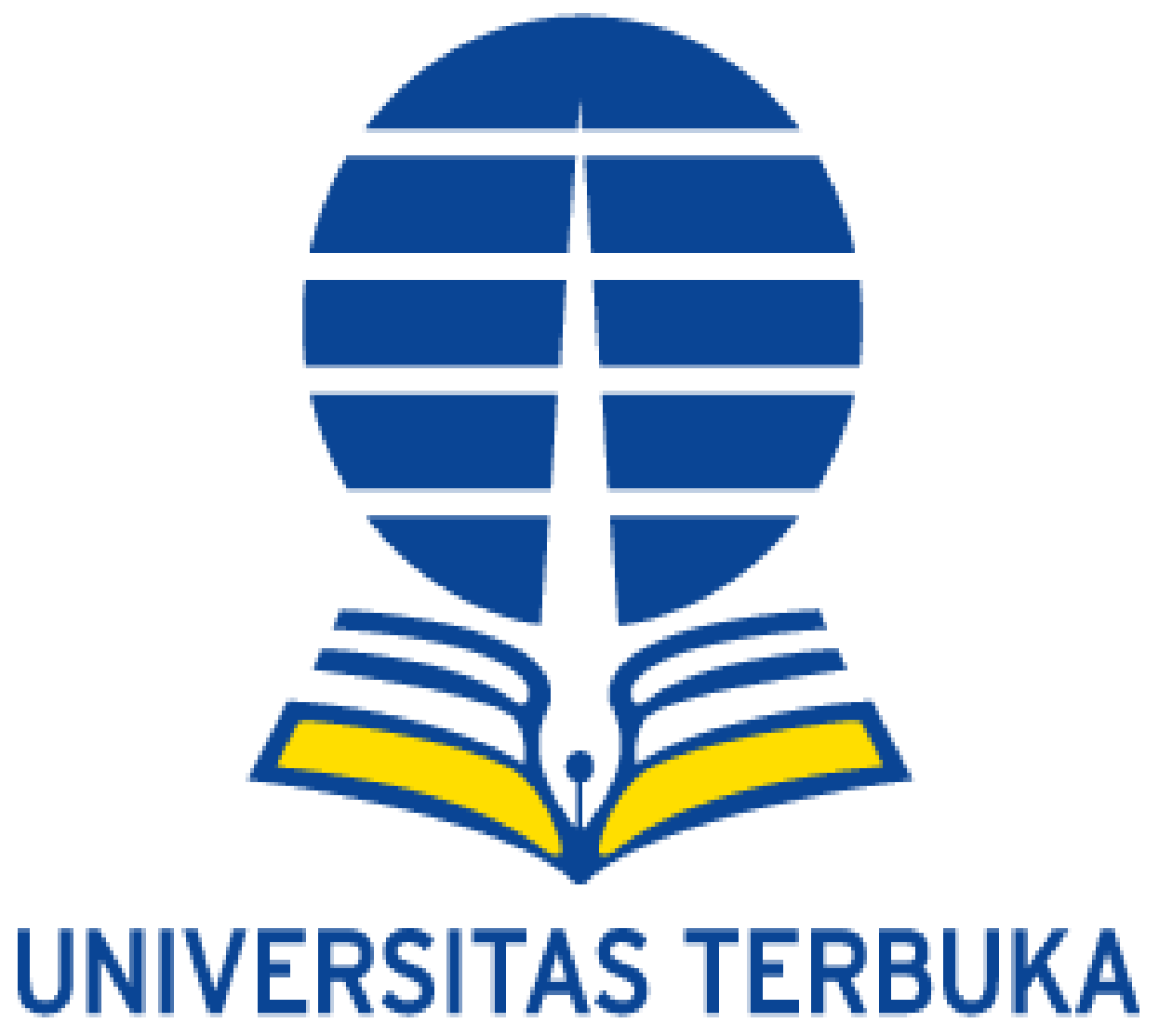

Disusun oleh :

Kristina Tri Budi Asih

NIM : 040367115

PROGRAM STUDI MANAJEMEN PEMASARAN, JURUSAN AKUTANSI

FAKULTAS EKONOMI

UNIVERSITAS TERBUKA PURWOKERTO 2019 


\section{A. LATAR BELAKANG}

Makanan ringan atau cemilan merupakan makanan yang memiliki maksud untuk menghilangkan rasa lapar sesorang sementara waktu. Saat ini sudah banyak makanan ringan yang beredar di Purwokerto yang mempunyai bentuk, rasa, pengemasan, dan tampilan yang berbeda beda yang dibuat semenarik mungkin untuk menarik perhatian para konsumen. Konsumen dapat memilih dua macam tipe makanan yaitu makanan modern atau makanan tradisional. Makanan tradisional banyak dijumpai di pasar sedangkan makanan modern hanya dpat ditemukan di Mall, café ataupun tempat makan lainnya. Banyak masyarakat lebih memilih makanan modern karena lebih praktis, murah dan beranekaragaman.

Untuk tetap maju dalam persaingan perlu ditingkatkan kualitas produk, kualitas pelayanan, dan kepuasan para konsumen yamg akan mengacu kepada loyalitas konsumen. Kualitas produk adalah keunggulan produk yang berkaitan dengan apa yang diharapkan pelanggan.

Tidak hanya dengan dari kualitas produk yang dapatmempertahankan konsumen tetapi dengan kualitas pelayanan yang handal dapat menarik minat konsumen dalam pembelian produk.

Salah satu tempat usaha Jajanan Hits Purwokerto ini merupakan usaha yang dimulai dari usaha kecil yang hanya berniat untuk menambah penghasilan suami yang kini menjadi usaha yang semakin berkembang.

\section{B. Rumusan Masalah}

Berdasarkan latar belakang diatas dapat dirumuskan permasalahan berikut :

1. Apa profil dari usaha toko jajanan hits?

2. Apa saja jenis produk yang di jual dan harga berapa yang dijual?

3. Bentuk promosi seperti apa saja yang dilakukan?

4. Siapa saja konsumen yang membeli produk tersebut?

\section{Tujuan Penelitian}

Adapun tujuan dari penelitian sebagai berikut :

1. Mengetahui toko jajanan tesebut tergolong factor segmentasi yang mana. 
2. Mengetahui segmentasi apa saja yang perlu dilakukan agar usaha tersebut berada diposisi yang terbaik di pasar

\section{Hasil Penelitian dan Pembahasan}

1. Profil perusahaan :

Latar belakang adanya toko jajanan hits ini didirikan karena owner yang bernama Kiki ini berutujuan hanya ingin menambah penghasilan sendiri tanpa membebankan segala keperluannya ke suami dengan cara menjualkan makanan kekinian ataupun prodak tambahan lainnya seperti produk kecantikan.

2. Jenin produk dan harga :

Jenis jenis produk yang di jual seperti makanan mie lidi, makaroni ataupun makanan kekinian lainnya.

Harga yang ditawarkanpun masih tergolong tidak terlalu mahal yaitu kisaran harga $\operatorname{Rp} 15.000$ s/d Rp 500.000
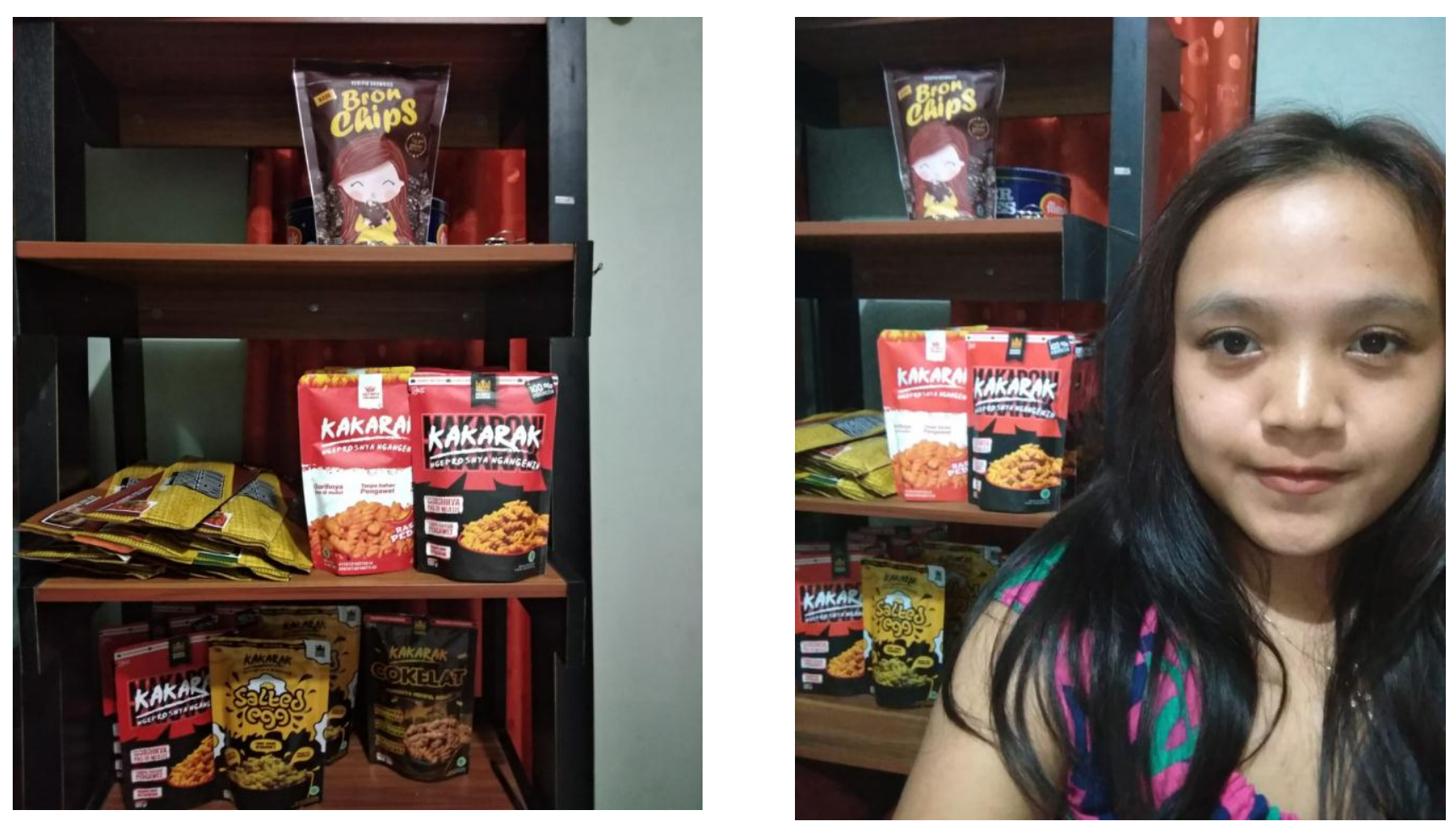

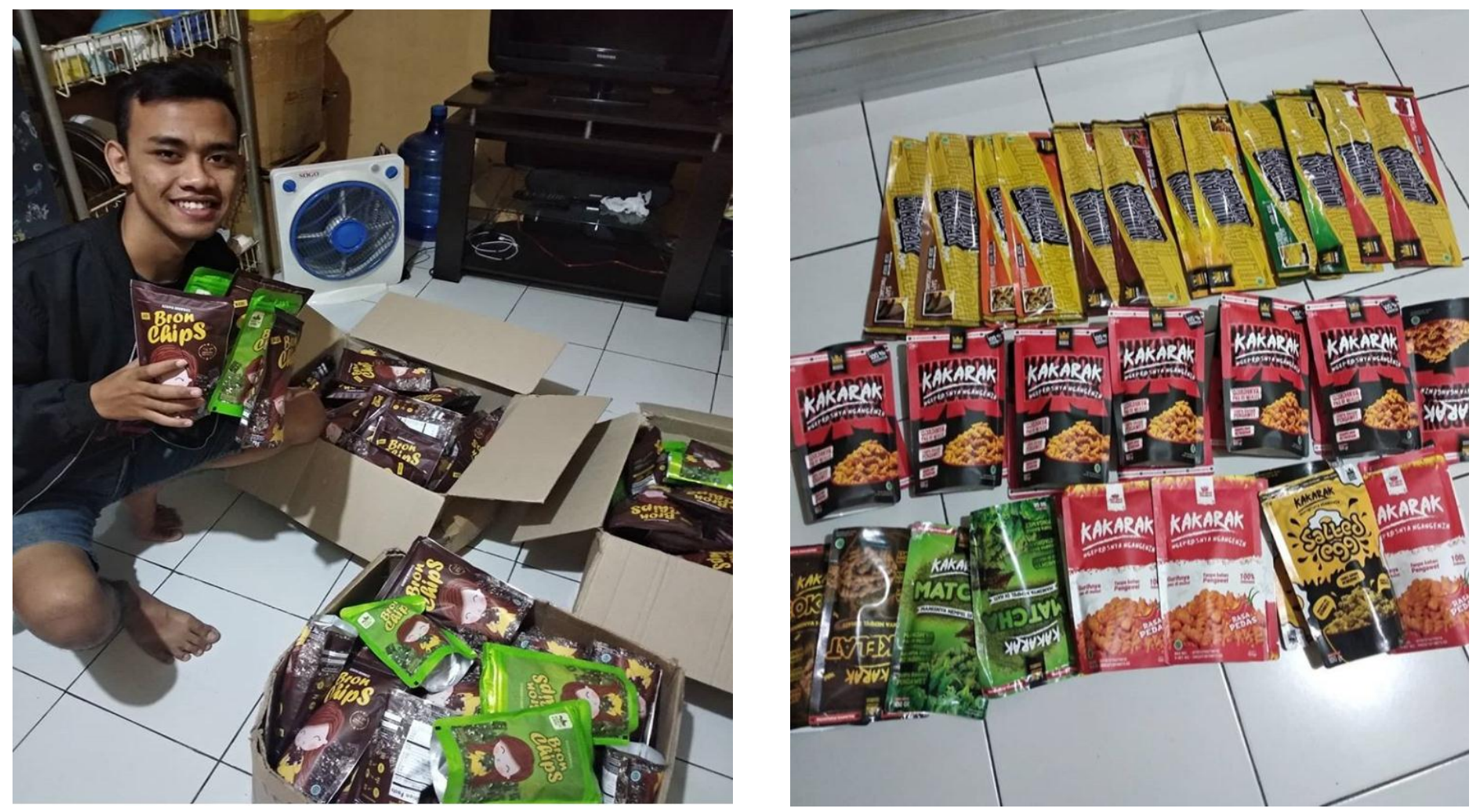

3. Bentuk promosi yang dilakukan :

Bentuk promosi yang dilakukan owner toko jajanan hits ini melalui social media seperti facebook,instagram, maupun social media lainnya.

Bentuk promosi juga dilakukan melalui 1 orang ke orang lain.

4. Siapa saja yang membeli produk :

Yang membeli produk ini dari kalangan anak kecil sampe orang tua.

Semua umur banyak yang menyukai jajanan ini.

\section{E. KESIMPULAN}

1. Segmentasi pasar konsumen :

Segmentasi geografis $=$ nasional merambah global $($ diekspor $)$

Segmentasi demografis $=$

- Usia : Semua usia

- Penghasilan : Terjangkau oleh semua kalangan ekonomi atas hingga bawah

- Jenis kelamin : Semua gender

- Kelas social : Semua kelas tingkat social 
Segmentasi Perilaku : Selain sebagai cemilan yang murah,enak dan harga yang terjangkau, makanan ini juga praktis untuk dibawa pergi jalan jalan

2. Strategi yang dilakukan untuk usaha jajanan hits ini terus berkembang dengan selalu aktiv promosi di social media dan selalu ada aneka jenis rasa jajanan agar orang tidak bosan dengan jenis ataupun rasa yang sama. Karena semakin banyak usaha usaha yang semakin ketat dalam persaingan perdagangan

Demikian laporan mengenai segmentasi pasar di toko jajanan hits,jika ada salah dalam tutur kata bahasa saya memohon maaf.

Terimakasih

\section{Referensi}

Fadillah, A., Sujana, S. and Sukartaatmadja, I., 2019. Kajian Minat Studi Lanjut Siswa-Siswi SMA dan SMK Kota Bogor Ke Perguruan Tinggi. JAS-PT (Jurnal Analisis Sistem Pendidikan Tinggi Indonesia), 3(1), pp.53-62.

Mulyana, M., 2019. MENGANALISIS PERILAKU KONSUMEN. Mulyana, M., 2019. STRATEGI PROMOSI DAN KOMUNIKASI.

Mulyana, M., Hidayat, L. and Puspitasari, R., 2019. Mengukur Pengetahuan Investasi Para Mahasiswa Untuk Pengembangan Galeri Investasi Perguruan Tinggi. JAS-PT (Jurnal Analisis Sistem Pendidikan Tinggi Indonesia), 3(1), pp.31-52.

Sulistiono, S., Nurendah, Y. and Mulyana, M., 2019. Mengukur Minat Studi Siswa SMA dan SMK di Kota Bogor Pada Program Studi Kewirausahaan. JAS-PT (Jurnal Analisis Sistem Pendidikan Tinggi Indonesia), 3(1), pp.1-12.

Sukartaatmadja, I., Thoyibah, H., Mulyana, M. and Yusdira, A., 2019. PELATIHAN DIGITAL LIBRARY BAGI PENGELOLA PERPUSTAKAAN PERGURUAN TINGGI SEBOGOR.

Setiawan, B., Puspitasari, R. and Manurung, T.M.S., 2016. The existence of Islamic banking in Indonesia from non-muslims perceptions. ASEAN Marketing Journal, pp.81-96.

Hidayat, L., Amwilla, A.Y. and Aprilia, A., 2015. Analisis Perputaran Modal Kerja, Perputaran Aktiva Terhadap Tingkat Pengembalian Modal. Jurnal Ilmiah Manajemen Kesatuan, 3(1).

Purba, J.H.V. and Munawar, A., 2008. Kajian Dampak Pelatihan terhadap Kinerja Karyawan. Jurnal Ilmiah Ranggagading (JIR), 8(2), pp.95-102.

Purba, J.H.V. and Hartoyo, S., 2018. Dampak Kenaikan Harga Minyak Bumi terhadap Permintaan CPO untuk Biodiesel dan Beberapa Aspek Pada Industri Kelapa Sawit Indonesia. JIMFE (Jurnal Ilmiah Manajemen Fakultas Ekonomi), 2(1), pp.37-49. 